\title{
PENGARUH KOMPENSASI DAN MOTIVASI KERJA TERHADAP KEPUASAN KERJA SERTA IMPLIKASINYA TERHADAP KINERJA PEGAWAI PADA DINAS PENDIDIKAN KABUPATEN KARAWANG
}

\author{
Soleh Adang Saputra \\ Universitas Singaperbangsa Karawang \\ Putra.deny@gmail.com
}

\begin{abstract}
ABSTRAK
penelitian ini bertujuan untuk mengetahui, menjelaskan dan menganalisis Kompensasi Dan Motivasi Kerja Terhadap Kepuasan Kerja Serta Implikasinya Pada Kinerja Pegawai serta pengaruh parsial dan simultan Kompensasi Dan Motivasi Kerja Terhadap Kepuasan Kerja Serta Implikasinya Pada Kinerja Pegawai Pada Dinas Pendidikan Kabupaten Karawang. Jumlah sampel yang diambil sebanyak 70 pegawai dengan teknik sampling jenuh. Tesis ini diharapkan dapat memberikan sumbangan bagi pengembangan bidang manajemen khususnya manajemen sumber daya manusia. Metode penelitian yang digunakan penulis dalam penulisan ini menggunakan metode deskriptif dan verifikatif, dari hasil analisis data penelitian diperoleh beberapa kesimpulan sebagai berikut: (1) Kompensasi pada Dinas Pendidikan Kabupaten Karawang dinyatakan baik, Motivasi pada Dinas Pendidikan Kabupaten Karawang sudah baik, Kepuasan kerja pada Dinas Pendidikan Kabupaten Karawang dinyatakan baik, Kinerja pegawai di Dinas Pendidikan Kabupaten Karawang dinyatakan baik. (2) Kompensasi secara parsial mempunyai pengaruh yang positif dan signifikan terhadap Kepuasan kerja.(3) Motivasi Secara parsial mempunyai pengaruh yang positif dan signifikan terhadap kepuasan kerja. (4) Kompensasi secara parsial mempunyai pengaruh yang positif dan signifikan terhadap Kinerja (5) Motivasi Secara parsial mempunyai pengaruh yang positif dan signifikan terhadap Kinerja. (6)Koefisien jalur variabel Kepuasan kerja terhadap kinerja pegawai adalah sebesar 0,424 dan besar total pengaruhnya (langsung) sebesar 0,180 atau 18\%.(7) Kompensasi dan Motivasi secara simultan mempunyai pengaruh yang positif dan signifikan terhadap Kepuasan kerja. (8) Kompensasi, Motivasi dan Kepuasan Kerja secara simultan mempunyai pengaruh positif dan signifikan terhadap Kinerja.
\end{abstract}

Kata Kunci: Kompensasi, Motivasi, Kepuasan Kerja, Kinerja

\section{A. PENDAhULUAN}

Kinerja pegawai merupakan prestasi kerja atau prestasi sesungguhnya yang dicapai pegawai, dengan aspeknya yaitu kemampuan, kualitas dan kuantitas pekerjaan serta disiplin pegawai. Berikut ini adalah data capaian kinerja pegawai Dinas Pendidikan Kabupaten Karawang yang terdiri dari Jumlah kerja, Kualitas kerja, Pengetahuan kerja, Kreativitas, Kerjasama, Loyalitas, Inisiatif, dan Kualitas pribadi dapat dilihat dari tabel 1.1 dibawah ini : 
Tabel 1

Kinerja Pegawai tahun 2016

\begin{tabular}{|c|c|c|c|}
\hline Indikator & Target & Realisasi & Keterangan \\
\hline Jumlah kerja & $85 \%$ & $70 \%$ & $\begin{array}{l}\text { Jumlah pekerjaan yang berhasil } \\
\text { dikerjakan dengan baik }\end{array}$ \\
\hline Kualitas kerja & $80 \%$ & $60 \%$ & $\begin{array}{l}\text { Bobot pekerjaan yang sesuai } \\
\text { dengan rencana kerja }\end{array}$ \\
\hline $\begin{array}{l}\text { Pengetahuan } \\
\text { kerja }\end{array}$ & $95 \%$ & $72 \%$ & $\begin{array}{l}\text { Jumlah pegawai yang bekerja } \\
\text { sesuai kemampuan yang dimiliki }\end{array}$ \\
\hline Kreativitas & $85 \%$ & $76 \%$ & $\begin{array}{l}\text { Rata-rata jumlah ide/gagasan } \\
\text { perorang perbulan }\end{array}$ \\
\hline Kerjasama & $95 \%$ & $75 \%$ & $\begin{array}{l}\text { Jumlah orang yang bisa } \\
\text { bekerjasama dengan baik }\end{array}$ \\
\hline Loyalitas & $85 \%$ & $77 \%$ & Rata-rata kehadiran pegawai \\
\hline Inisiatif & $80 \%$ & $70 \%$ & $\begin{array}{l}\text { Jumlah penyelesaikan tugas baru } \\
\text { dengan baik }\end{array}$ \\
\hline $\begin{array}{l}\text { Kualitas } \\
\text { pribadi }\end{array}$ & $80 \%$ & $72 \%$ & $\begin{array}{l}\text { Bobot pekerjaan yang sesuai } \\
\text { profesi kerja }\end{array}$ \\
\hline
\end{tabular}

Sumber : Subag Kepegawaian 2017

Berdasarkan pada penilaian kinerja pada tabel diatas dapat disimpulkan bahwa ketercapaian target masih belum terealisasi dengan baik. Tinggi rendahnya kinerja pegawai bergantung kepada beberapa aspek, berdasarkan pengamatan penulis dilapangan, dapat diambil kesimpulan bahwa belum optimalnya kinerja diduga tingkat pengawasan kerja yang dilakukan oleh pimpinan belum berjalan secara efektif. Sehingga ketercapaian target kerja belum bisa terlaksana maksimal. Hal ini dikarenakan dengan banyaknya kegiatan sekolah yang dilakukan dengan personil yang minim akan berdampak pada ketercapaian target pekerjaan

Salah satu penentu tinggi rendahnya kinerja pegawai, diduga dipengaruhi oleh kepuasan kerja. Faktor kepuasan kerja secara simultan maupun parsial berpengaruh signifikan terhadap kinerja pegawai. Hasil penelitian Nicholson and Goodge (1998) yang dikutif Ivancevich (2001:45). Berikut ini adalah hasil prasurvey kepuasan kerja pegawai dapat dilihat pada tabel dibawah ini:

Tabel. 2

Prasurvey Kepuasan Kerja Pegawai

\begin{tabular}{|c|c|c|c|c|c|c|c|c|}
\hline \multirow{2}{*}{ No } & \multirow{2}{*}{ Dimensi } & \multicolumn{4}{|c|}{ Frekuensi } & \multicolumn{2}{|c|}{ Rata Rata } & Kategori \\
\hline & & 5 & 4 & 3 & 2 & 1 & & \\
\hline 1 & $\begin{array}{l}\text { Beban Kerja } \\
\text { Tingkat beban kerja yang } \\
\text { Diterima pegawai }\end{array}$ & 2 & 5 & 8 & 4 & 1 & 3,150 & Cukup Baik \\
\hline 2 & $\begin{array}{l}\text { Pengawasan } \\
\text { Tingkat pelaksanaan } \\
\text { pengawasan } \\
\text { kerja }\end{array}$ & 3 & 5 & 3 & 1 & 8 & 2,700 & Cukup Baik \\
\hline 3 & $\begin{array}{l}\text { Kesempatan Untuk Maju } \\
\text { Tingkat peluang untuk }\end{array}$ & 1 & 3 & 12 & 3 & 1 & 3,000 & Cukup Baik \\
\hline
\end{tabular}




\begin{tabular}{|c|c|c|c|c|c|c|c|c|}
\hline \multirow{2}{*}{ No } & \multirow{2}{*}{ Dimensi } & \multicolumn{4}{|c|}{ Frekuensi } & \multicolumn{2}{|c|}{ Rata Rata } & \multirow[t]{2}{*}{ Kategori } \\
\hline & & 5 & 4 & 3 & 2 & $\mathbf{1}$ & & \\
\hline & Meningkatkan karir & & & & & & & \\
\hline 4 & $\begin{array}{l}\text { Insentif } \\
\text { Tingkat pemberian insentif }\end{array}$ & 4 & 3 & 5 & 3 & 5 & 2,900 & Cukup Baik \\
\hline 5 & Lingkungan Sosial & 1 & 4 & 11 & 4 & 0 & 3,100 & Cukup Baik \\
\hline
\end{tabular}

Sumber: Hasil Prasurvey 2017

Berdasarkan data hasil prasurvey tersebut menunjukan bahwa kepuasan kerja para pegawai Dinas Pendidikan Kabupaten Karawang secara keseluruhan masih belum optimal, aspek terlemah menurut persepsi dari responden menunjukan tingkat pengawasan dari pimpinan masih lemah, hal tersebut berarti bahwa peran dari pimpinan dalam memberikan pengawasan ataupun berpartisipasi dengan para bawahan dinilai masih kurang, sedangkan aspek terlemah kedua adalah mengenai insentif yang diberikan berdasarkan hasil pra survey dinyatakan rendah.

Salah satu unsur yang mempengaruhi kepuasan kerja pegawai adalah kompensasi. Baik kompensasi finansial maupun non finansial. Dalam menentukan besarnya kompensasi yang diterima oleh pegawai, perlu dipertimbangkan banyak hal. Milkovich (2002:13) menciptakan suatu model yang menggambarkan faktor-faktor yang terlibat dalam pengambilan keputusan dalam hal kompensasi bagi pegawai.

Berikut ini adalah data hasil prasurvey mengenai kompensasi berdasarkan persepsi dari 20 orang pegawai dapat dilihat pada tabel dibawah ini:

Tabel. 3

\section{Prasurvey Kompensasi Pegawai}

\begin{tabular}{|c|c|c|c|c|c|c|c|c|}
\hline \multirow{2}{*}{ No } & \multirow{2}{*}{ Dimensi } & \multicolumn{5}{|c|}{ Frekuensi } & \multirow{2}{*}{ Rata Rata } & \multirow{2}{*}{ Kategori } \\
\hline & & 5 & 4 & 3 & 2 & 1 & & \\
\hline 1 & $\begin{array}{l}\text { Finansial } \\
\text { Tingkat kecukupan } \\
\text { pemberian reward } \\
\text { Atau bonus atas hasil kerja }\end{array}$ & 3 & 5 & 3 & 1 & 8 & 2,7 & Cukup Baik \\
\hline 2 & $\begin{array}{l}\text { Non Finansial } \\
\text { Tingkat penghargaan dari } \\
\text { pimpinan } \\
\text { Atas hasil kerja yang } \\
\text { dicapai }\end{array}$ & 4 & 3 & 5 & 3 & 5 & 2,9 & Cukup Baik \\
\hline
\end{tabular}

Sumber: Hasil prasurvey 2017

Berdasarkan hasil pras survey menunjukan dimensi kompensasi finansial (langsung), maupun dimensi non finansial (tidak langsung) dari variabel kompensasi masih belum optimal, berdasarkan pengamatan dilapangan melalui wawancara dengan beberapa pegawai, dapat disimpulkan bahwa besaran gaji yang diterima pada umumnya bervariatif, dilihat dari besaran gaji yang diberikan sebagian besar pegawai mempersepsikan cukup baik, gaji yang diterima dirasakan sudah cukup.

Fungsi organisasi yang dijalankan dengan baik akan melahirkan motivasi pegawai yang baik sehingga meningkatkan kinerja setiap pegawai adapun data observasi motivasi kerja pegawai seperti pada data table dibawah ini:

\section{Tabel 4}

Data Prasurvey Motivasi Kerja Pegawai 


\begin{tabular}{|c|c|c|c|c|c|c|c|}
\hline \multirow{2}{*}{ Dimensi } & \multicolumn{5}{|c|}{ Frekuensi } & \multirow{2}{*}{$\begin{array}{c}\text { Rata- } \\
\text { rata }\end{array}$} & \multirow{2}{*}{ Kriteria } \\
\hline & 5 & 4 & 3 & 2 & 1 & & \\
\hline $\begin{array}{l}\text { Kebutuhan Berprestasi } \\
\text { Tingkat kemampuan untuk mencapai } \\
\text { hubungan kepada standar kerja yang telah } \\
\text { ditentukan serta perjuangan Pegawai } \\
\text { menuju keberhasilan }\end{array}$ & 3 & 3 & 7 & 6 & 1 & 3,05 & $\begin{array}{c}\text { Cukup } \\
\text { Baik }\end{array}$ \\
\hline $\begin{array}{l}\text { Kebutuhan Berafiliasi } \\
\text { hasrat untuk bersahabat dan mengenal } \\
\text { lebih dekat rekan atau para Pegawai di } \\
\text { dalam organisasi }\end{array}$ & 1 & 1 & 12 & 6 & 0 & 2,85 & $\begin{array}{c}\text { Cukup } \\
\text { Baik }\end{array}$ \\
\hline $\begin{array}{l}\text { Kebutuhan akan Kekuasaan } \\
\text { Tingkat kebutuhan dalam mencapai } \\
\text { kekuasaan atau otoritas kerja serta } \\
\text { kebutuhan untuk membuat orang } \\
\text { berperilaku dalam keadaan yang wajar dan } \\
\text { bijaksana di dalam tugasnya masing- } \\
\text { masing }\end{array}$ & 1 & 4 & 7 & 3 & 5 & 2,65 & $\begin{array}{c}\text { Cukup } \\
\text { Baik }\end{array}$ \\
\hline
\end{tabular}

Sumber: Hasil Penelitian Pendahuluan 2017

Dari data table diatas dapat disimpulkan bahwa motivasi kerja pegawai berada pada kategori cukup baik.Kebutuhan akan berprestasi berada pada kategori cukup baik dimana pegawai pada umumnya bekerja masih hanya sebatas memenuhi kebutuhan hidupnya dan juga hanya melaksanakan tugas dan tanggung jawabnya dimana para pegawai pada umumnya belum terlalu memperhatikan prestasi mereka dalam bekerja.

\section{B. TINJAUAN PUSTAKA}

\section{Kinerja Pegawai}

Menurut Amstrong dan Baron dalam Irham Fahmi (2011:2), Kinerja adalah hasil pekerjaan yang mempunyai hubungan kuat dengan tujuan strategis organisasi, kepuasan konsumen dan memberikan kontribusi ekonomi.

Kemudian Indra Bastian yang dikutip oleh Irham Fahmi (2011:2), Kinerja adalah gambaran mengenai tingkat pencapaian pelaksanaan suatu kegiatan atau program dan kebijakan dalam mewujudkan sasaran, tujuan, misi dan visi organisasi yang tertuang dalam perumusan skema strategis (strategic planning) suatu organisasi.

Menurut Irham Fahmi (2013:226) bahwa kinerja adalah hasil yang diperoleh suatu organisasi baik organisasi tersebut bersifat profit oriented dan non profit oriented yang dihasilkan selama satu periode waktu. 
Menurut Mahsum dalam buku Masana Sembiring (2012:81) kinerja adalah gambaran mengenai tingkat pencapaian pelaksanaan suatu kegiatan /program / kebijakan dalam mewujudkan sasaran, tujuan, misi, dan visi organisasi.

Menurut Riani (2011:97) bahwa kinerja adalah hasil kerja yang dapat dicapai oleh seseorang atau kelompok orang dalam suatu perusahaan sesuai dengan wewenang dan tanggung jawab masing-masing dalam upaya pencapaian tujuan perusahaan secara legal, tidak melanggar hukum dan tidak bertentangan dengan moral dan etika.

Sedangkan menurut (Armstrong dan Baron dalam Wibowo, 2010:2) dalam tesis Doedy Hidayat S (2011:28), Kinerja adalah tentang melakukan pekerjaan dan hasil yang dicapai dari pekerjan tersebut. Kinerja adalah tentang apa yang dikerjakan dan bagaimana cara mengerjakannya. Kinerja merupakan hasil pekerjaan yang mempunyai hubungan kuat dengan tujuan strategis organisasi, kepuasan konsumen, dan memberikan kontribusi ekonomi.

Menurut Veithzal Rivai (2010:16) menyatakan bahwa:

Kinerja adalah hasil kerja yang dapat dicapai oleh seseorang atau kelompok orang dalam suatu perusahaan sesuai dengan wewenang dan tanggung jawab masing-masing dalam upaya pencapaian tujuan perusahaan secara legal, dan tidak melanggar hukum dan tidak bertentangan dengan moral atau etika.

Sedangkan definisi kinerja menurut Tjutju Yunarsih dan Suwanto (2008:161) menyatakan bahwa "Kinerja merupakan prestasi yang nyata ditampilkan seseorang setelah yang bersangkutan menjalankan tugas dan perannya dalam organisasi”.

Selanjutnya Anwar Prabu Mangkunegara (2008:67), Kinerja adalah hasil kerja secara kualitas dan kuantitas yang dicapai oleh seorang pegawai dalam melaksanakan tugasnya sesuai dengan tanggung jawab yang diberikan kepadanya.

\section{Kompensasi}

Slamet (2007: 261) "Kompensasi merupakan setiap bentuk penghargaan yang diberikan kepada pegawai sebagai balas jasa atas kontribusi yang mereka berikan kepada organisasi".

Menurut William B. Werther dan Keith Davis (dalam Malayu Hasibuan, 2013:119):

Compensation is what employee receive in exchange of their work. Whether hourly wages or periodic salaries, the personnel department usually design and administers employee compensation. (Kompensasi adalah apa yang seorang pekerja terima sebagai balasan dari pekerjaan yang diberikannya. Baik upah per jam ataupun gaji periodik didesain dan dikelola oleh bagian personalia).

Menurut Tohardi (dalam Edy Sutrisno, 2014:182)

Mengemukakan bahwa kompensasi dihitung berdasarkan evaluasi pekerjaan, perhitungan kompensasi berdasarkan evaluasi pekerjaan tersebut dimaksudkan untuk mendapatkan pemberian kompensasi yang mendekati kelayakan (worth) dan keadilan (equity).

Menurut Edwin B. Flippo (dalam Malayu Hasibuan, 2013:119)

Wages is defined as the adequate and equitable renumeration of personnel for their constribution to organizational objectives. (Upah didefinisikan sebagai balas jasa yang adil dan layak diberikan kepada para pekerja atas jasa-jasanya dalam mencapai tujuan organisasi.)

\section{Motivasi}

Menurut Joko Purnomo (2008:48-50) dalam penelitiannya mengenai motivasi kerja dan lingkungan kerja mengatakan "variable motivasi kerja dan lingkungan memiliki pengaruh yang signifikan terhadap kinerja karyawan."

Menurut pendapat yang dikemukakan oleh Gitosudarmo (2011:134) motivasi adalah: 
Suatu faktor yang mendorong seseorang untuk melakukan suatu aktivitas tertentu, oleh karena itu motivasi seringkali diartikan sebagai faktor pendorong perilaku seseorang. Pendorong perilakau seseorang biasanya kebutuhan serta keinginan yang hendak dicapai.

Menurut Wilson Bangun (2012:313), bahwa motivasi adalah suatu tindakan untukmempengaruhi orang lain agar berperilaku secara teratur.

Menurut Stephen P. Robbins, dkk dalam Winardi (2011:2) "Motivasi adalah kesediaan untuk melaksanakan uapaya tinggi untuk mencaapai tujuan-tujuan keorganisasian, yang dikondisikan oleh kemampuan upaya untuk memenuhi kebutuhan individual tertentu."

Menurut Gray, dkk dalam Winardi (2011:2) "Motivasi merupakan hasil sejumlah proses yang bersifat internal atau eksternal bagi seorang individu, yang menyebabkan timbulnya sikap entusiasme dan persistensi dalam hal melaksanakan kegiatan-kegiatan tertentu."

\section{Kepuasan Kerja}

Menurut Newstrom dalam Khikmawati (2015:32) bahwa job satisfaction is the favorableness or unfavorableness with employes view their work. Kepuasan kerja berarti perasaan mendukung atau tidak mendukung yang dialami karyawan dalam bekerja. Sementara itu, menurut Happock dalam Parimita (2013:261) mengatakan "job satisfaction as any combination of psychological and environmental circumstances that cause a person thruthfully to say, I am satisfied with my job".

Khaerul umam (2010:192) menyatakan bahwa:

Kepuasan kerja merupakan sikap (positif) tenaga kerja terhadap pekerjaannya, yang timbul berdasarkan penilaian terhadap situasi kerja. Penilaian tersebut dapat dilakukan terhadap salah satu pekerjaannya.Penilaian dilakukan sebagai rasa menghargai dalam mencapai salah satu nilai-nilai penting dalam pekerjaan. Karyawan yang puas lebih menyukai situasi kerjanya daripada karyawan yang tidak puas, yang tidak menyukai situasi kerjanya.

Sedangkan menurut Veithzal (2010:856) bahwa kepuasan kerja merupakan evaluasi yang menggambarkan seseorang atas perasaan sikapnya senang atau tidak senang, puas atau tidak puas dalam bekerja. Handoko (2011:193) menyatakan bahwa kepuasan kerja adalah keadaan emosional yang menyenangkan atau tidak menyenangkan dengan mana para karyawan memandang pekerjaan mereka .

Keith davis sebagaimana dikutip oleh Anwar Prabu mangkunegara (2008:117) mengemukakan bahwa "job satisfaction Is the favorableness or unfavorableness with employees view their work". Yang artinya adalah kepuasan kerja yaitu adalah perasaan menyokong atau tidak menyokong yang dialami pegawai dalam bekerja. Sedangkan Wexley dan Yuki mendefinisikan kepuasan kerja sebgai berikut "is the way an employees feels about his or her job”, yang artinya adalah cara pegawai merasakan dirinya atau pekerjaannya.

\section{Hipotesis Penelitian}

Berdasarkan Tinjauan pustaka, hasil penelitian terdahulu dan kerangka pemikiran di atas, maka dirumuskan hipotesis penelitian sebagai berikut :

1. Terdapat pengaruh Kompensasi terhadap kepuasan kerja pegawai Dinas Pendidikan Kabupaten Karawang .

2. Terdapat pengaruh Motivasi Kerja terhadap kepuasan kerja pegawai Dinas Pendidikan Kabupaten Karawang .

3. Terdapat pengaruh Kepuasan kerja terhadap kinerja pegawai Dinas Pendidikan Kabupaten Karawang 
4. Terdapat Pengaruh Kompensasi Terhadap Kinerja Pegawai Dinas Pendidikan Karawang

5. Terdapat Pengaruh Motivasi Kerja Terhadap Kinerja Pegawai Dinas Pendidikan Karawang

6. Terdapat pengaruh secara simultan Kompensasi dan Motivasi kerja terhadap Kepuasan kerja pegawai Dinas Pendidikan Kabupaten Karawang .

7. Terdapat Pengaruh Simultan Kompensasi, Motivasi Kerja dan Kepuasan Kerja Terhadap Kinerja Pegawai Dinas Pendidikan Karawang.

\section{METODE PENELITIAN DAN ANALISIS DATA}

Metode penelitian pada dasarnya merupakan cara ilmiah untuk mendapatkan data dengan tujuan dan kegunaan tertentu. Cara ilmiah kegiatan penelitian itu didasarkan pada ciri-ciri keilmuan, yaitu rasional, empiris, dan sistematis (Sugiyono 2012:2). Dalam penelitian ini menggunakan metode penelitian deskriptif dan verifikatif. Menurut Sugiyono (2012:35), penelitian deskriptif adalah penelitian yang dilakukan untuk mengetahui nilai variabel mandiri, baik satu variabel atau lebih (independent) tanpa membuat perbandingan atau menghubungkan dengan variabel yang lain. Penelitian verifikatif menurut Sugiyono (2012:3) bahwa metode penelitian kuantitatif yang digunakan untuk penelitian populasi atau sampel tertentu, dan analisis data bersifat statistik dengan tujuan untuk menguji hipotesis yang telah ditetapkan. Tujuan dari penelitian deskriptif adalah untuk memperoleh gambaran secara sistematis mengenai Kompensasi dan motivasi kerja, kepuasan kerja sebagai variable intervening serta kinerja sebagai variabel terikat, sedangkan secara verifikatif bertujuan untuk menguji hipotesis dengan perhitungan statistik.

\section{Populasi}

Populasi adalah wilayah generalisasi yang terdiri dari objek/subjek yang mempunyai kuantitas dan karakteristik tertentu yang ditetapkan oleh peneliti untuk mempelajari dan kemudian ditarik kesimpulan (Sugiono, 2012:117). Populasi dalam penelitian ini terdiri dari seluruh pegawai pada dinas pendidikan kabupaten karawang, yang terdiri dari 70 orang.

\section{Sampel}

Menurut Sugiyono (2012:149) Sampel adalah bagian jumlah dan karakteristik yang dimiliki oleh populasi tersebut. Pengambilan sampel yang dilakukan didalam penelitian ini adalah dengan menggunakan metode sampling jenuh. Semua anggota populasi dijadikan sampel untuk membuat generalisasi dengan kesalahan yang relative kecil. Dengan jumlah populasi pegawai sebanyak 70 orang. Maka sampel yang digunakan sama yaitu 70 orang. (Sugiono, 2012:152).

\section{HASIL PENELITIAN}

\section{Profil Responden}

Karakteristik responden dalam penelitian ini dapat dijelaskan sebagai berikut

Tabel 5

Jumlah Responden Berdasarkan Jenis Kelamin

\begin{tabular}{|c|c|c|c|}
\hline No. & Jenis Kelamin & Jumlah & Presentase \\
\hline 1 & Laki-laki & 42 & $60 \%$ \\
\hline 2 & Perempuan & 28 & $40 \%$ \\
\hline & Jumlah & 70 & 100 \\
\hline
\end{tabular}

Sumber : Hasil Pengolahan Data SPSS, 2017

Tabel 6

Jumlah Responden Berdasarkan Usia Responden 


\begin{tabular}{|c|c|c|c|}
\hline No. & Usia & Jumlah & Presentase \\
\hline 1 & $17-25$ Tahun & 15 & $21,4 \%$ \\
\hline 2 & $26-45$ Tahun & 50 & $71,4 \%$ \\
\hline 3 & $>45$ Tahun & 5 & $7,2 \%$ \\
\hline & Jumlah & 70 & 100 \\
\hline
\end{tabular}

Sumber : Hasil Pengolahan Data SPSS, 2017

\section{Pengujian Keabsahan Data Uji Validitas}

Tabel 7

Hasil Uji Validitas Variabel Kompensasi $\left(\mathbf{X}_{1}\right)$

\begin{tabular}{|c|l|c|c|c|}
\hline No & \multicolumn{1}{|c|}{ Indikator } & r Hitung & r Kritis & Keterangan \\
\hline 1 & Gaji & 0,488 & 0,3 & Valid \\
\hline 2 & Bonus & 0,757 & 0,3 & Valid \\
\hline 3 & Tunjangan Transport & 0,545 & 0,3 & Valid \\
\hline 4 & Tunjangan pengobatan & 0,431 & 0,3 & Valid \\
\hline 5 & Tunjangan Perumahan & 0,517 & 0,3 & Valid \\
\hline 6 & Tunjangan Hari Tua & 0,612 & 0,3 & Valid \\
\hline 7 & Time of Benefit & 0,745 & 0,3 & Valid \\
\hline 8 & Beasiswa Pendidikan & 0,704 & 0,3 & Valid \\
\hline 9 & Tunjangan Hari raya & 0,566 & 0,3 & Valid \\
\hline 10 & Pakaian Dinas & 0,608 & 0,3 & Valid \\
\hline 11 & Family Gathering & 0,504 & 0,3 & Valid \\
\hline 12 & Fasilitas Kantor & 0,760 & 0,3 & Valid \\
\hline 13 & Kafetaria & 0,738 & 0,3 & Valid \\
\hline 14 & Koperasi Pegawai & 0,568 & 0,3 & Valid \\
\hline
\end{tabular}

Sumber :

Hasil

Pengolahan Data SPSS, 2017

Tabel 8

Hasil Validitas Variabel Motivasi $\left(\mathbf{X}_{2}\right)$

\begin{tabular}{|c|l|c|c|c|}
\hline No & \multicolumn{1}{|c|}{ Indikator } & r Hitung & r Kritis & Keterangan \\
\hline 1 & $\begin{array}{l}\text { Kompensasi yang } \\
\text { memadai }\end{array}$ & 0,653 & 0,3 & Valid \\
\hline 2 & Dihormati orang lain & 0,692 & 0,3 & Valid \\
\hline 3 & $\begin{array}{l}\text { Penghargaan terhadap } \\
\text { prestasi }\end{array}$ & 0,594 & 0,3 & Valid \\
\hline 4 & Kondisi kerja & 0,671 & 0,3 & Valid \\
\hline 5 & Hubungan kerja & 0,615 & 0,3 & Valid \\
\hline 6 & Pimpinan yang adil & 0,583 & 0,3 & Valid \\
\hline 7 & Partisipasi kelompok & 0,746 & 0,3 & Valid \\
\hline 8 & Hak otonomi & 0,779 & 0,3 & Valid \\
\hline 9 & Jabatan & 0,369 & 0,3 & Valid \\
\hline 10 & Umpan balik & 0,613 & 0,3 & Valid \\
\hline 11 & Variasi pekerjaan & 0,676 & 0,3 & Valid \\
\hline
\end{tabular}




\begin{tabular}{|c|l|c|c|c|}
\hline 12 & Pengarahan pekerjaan & 0,477 & 0,3 & Valid \\
\hline 13 & $\begin{array}{l}\text { Keterampilan dan } \\
\text { kecakapan }\end{array}$ & 0,646 & 0,3 & Valid \\
\hline 14 & Perilaku yang baik & 0,571 & 0,3 & Valid \\
\hline
\end{tabular}

Sumber :

Hasil

Pengolahan Data SPSS, 2017

Tabel 9

Hasil Uji Validitas Variabel Kepuasan Kerja (Y)

\begin{tabular}{|c|l|c|c|c|}
\hline No & \multicolumn{1}{|c|}{ Indikator } & r Hitung & r Kritis & Keterangan \\
\hline 1 & Karakteristik pekerjaan & 0,345 & 0,3 & Valid \\
\hline 2 & Pemenuhan kebutuhan & 0,634 & 0,3 & Valid \\
\hline 3 & Beban kerja & 0,759 & 0,3 & Valid \\
\hline 4 & Peluang promosi & 0,648 & 0,3 & Valid \\
\hline 5 & Keleluasaan & 0,683 & 0,3 & Valid \\
\hline 6 & Penghargaan & 0,556 & 0,3 & Valid \\
\hline 7 & Kesesuaian pekerjaan & 0,737 & 0,3 & Valid \\
\hline 8 & kesempatan maju & 0,757 & 0,3 & Valid \\
\hline 9 & Keadilan & 0,442 & 0,3 & Valid \\
\hline 10 & Apresiasi & 0,490 & 0,3 & Valid \\
\hline 11 & Tuntutan tugas & 0,530 & 0,3 & Valid \\
\hline 12 & Ganjaran yang pantas & 0,667 & 0,3 & Valid \\
\hline 13 & Suasana kerja & 0,766 & 0,3 & Valid \\
\hline 14 & Keamanan kerja & 0,605 & 0,3 & Valid \\
\hline
\end{tabular}

Sumber:

Hasil

Pengolahan Data SPSS, 2017

Tabel 10

Hasil Uji Validitas Variabel Kinerja (Z)

\begin{tabular}{|c|l|c|c|c|}
\hline No & \multicolumn{1}{|c|}{ Indikator } & r Hitung & r Kritis & Keterangan \\
\hline 1 & Karakteristik pekerjaan & 0,345 & 0,3 & Valid \\
\hline 2 & Pemenuhan kebutuhan & 0,634 & 0,3 & Valid \\
\hline 3 & Beban kerja & 0,759 & 0,3 & Valid \\
\hline 4 & Peluang promosi & 0,648 & 0,3 & Valid \\
\hline 5 & Keleluasaan & 0,683 & 0,3 & Valid \\
\hline 6 & Penghargaan & 0,556 & 0,3 & Valid \\
\hline 7 & Kesesuaian pekerjaan & 0,737 & 0,3 & Valid \\
\hline 8 & kesempatan maju & 0,757 & 0,3 & Valid \\
\hline
\end{tabular}




\begin{tabular}{|c|l|c|c|c|}
\hline 9 & Keadilan & 0,442 & 0,3 & Valid \\
\hline 10 & Apresiasi & 0,490 & 0,3 & Valid \\
\hline 11 & Tuntutan tugas & 0,530 & 0,3 & Valid \\
\hline 12 & Ganjaran yang pantas & 0,667 & 0,3 & Valid \\
\hline 13 & Suasana kerja & 0,766 & 0,3 & Valid \\
\hline 14 & Keamanan kerja & 0,605 & 0,3 & Valid \\
\hline
\end{tabular}

Sumber :

Hasil

Pengolahan Data SPSS, 2017

\section{Uji Reliabilitas}

Tabel 11

Hasil Uji Reliabilitas

\begin{tabular}{|l|c|c|c|}
\hline \multicolumn{1}{|c|}{ Variabel } & rhitung & rkritis $_{\text {Kriteria }}$ & Reliabel \\
\hline Kompensasi $\left(\mathrm{X}_{1)}\right.$ & 0,904 & 0,700 & Reliabel \\
\hline Motivasi $\left(\mathrm{X}_{2}\right)$ & 0,913 & 0,700 & Reliabel \\
\hline Kepuasan Kerja(Y) & 0,909 & 0,700 & Reliabel \\
\hline Kinerja (Z) & 0,911 & 0,700 & \\
\hline
\end{tabular}

Sumber : Hasil Pengolahan Data SPSS, 2017

\section{Uji Normalitas}

Tabel 12

Hasil Uji Normalitas

\begin{tabular}{|c|c|c|c|}
\hline \multirow{2}{*}{ Variabel } & \multicolumn{2}{|c|}{ Kolmogorov-Smirnov } & \multirow{2}{*}{ Keterangan } \\
\hline & rhitung & $\mathbf{r}_{\text {kritis }}$ & \\
\hline $\operatorname{Kompensasi}\left(\mathrm{X}_{1}\right)$ & 0,113 & \multirow{4}{*}{0,050} & Distribusi Normal \\
\hline Motivasi $\left(\mathrm{X}_{2}\right)$ & 0,110 & & Distribusi Normal \\
\hline $\operatorname{Kepuasan} \operatorname{Kerja}(Y)$ & 0,121 & & Distribusi Normal \\
\hline Kinerja $(\mathrm{Z})$ & 0,093 & & Distribusi Normal \\
\hline
\end{tabular}

Sumber : Hasil Pengolahan Data SPSS,2017

\section{E. PEMBAHASAN HASIL PENELITIAN \\ Persamaan Jalur}

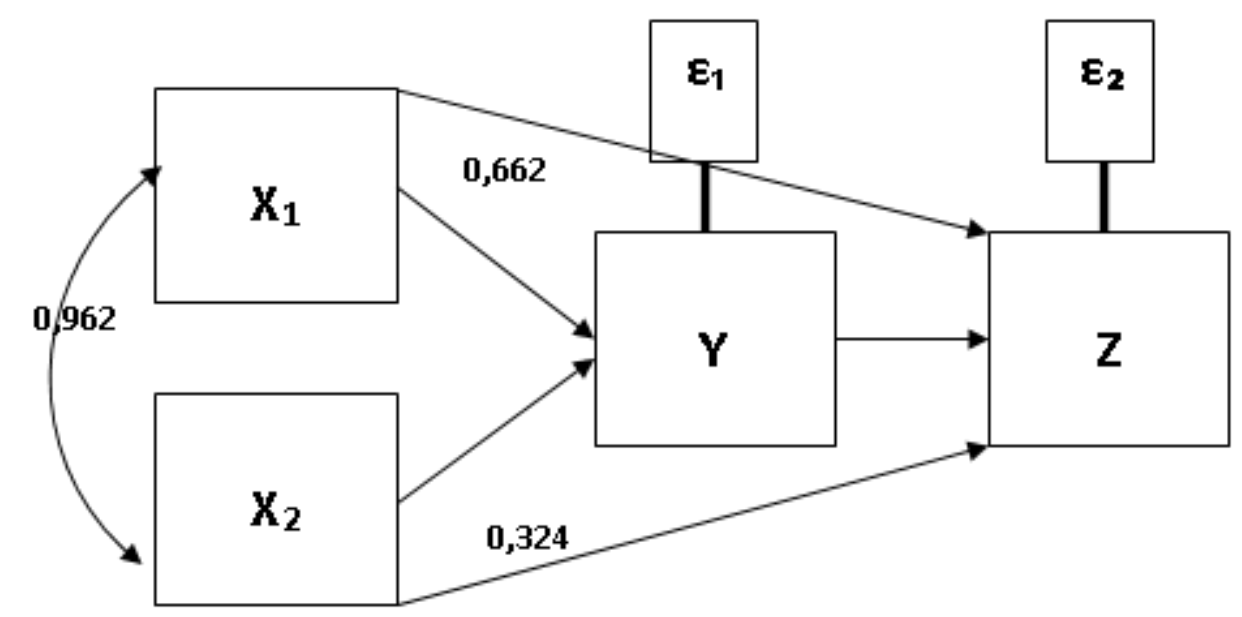

Gambar 1 


\section{Pengaruh Langsung dan Tidak Langsung Antar Variabel}

Berdasarkan gambar menunjukan bahwa besaran derajat positif asosiatif atau koefisien jalur variabel Kepemimpinan 0,354 lebih tinggi dari variabel Motivasi Kerja 0,339 dan Variable Kompensasi 0.291, artinya Kepemimpinan $\left(\mathrm{X}_{1}\right)$ lebih berpengaruh terhadap Kinerja Pegawai (Y) dibandingkan dengan Motivasi Kerja $\left(\mathrm{X}_{2}\right)$ dan Kompensasi $\left(\mathrm{X}_{3}\right)$. Adapun persamaan jalurnya adalah sebagai berikut:

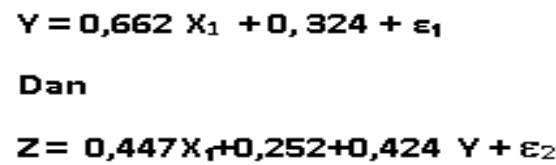

Keterangan :

$\mathrm{X}_{1}=$ Kompensasi

$\mathrm{X}_{2}=$ Motivasi

$\mathrm{Y}=$ Kepuasan Kerja

$\mathrm{Z}=$ Kinerja

$\varepsilon_{1} \quad=$ Variabel lain yang tidak diukur, tetapi mempengaruhi $\mathrm{Y}$

$\varepsilon_{2} \quad=$ Variabel lain yang tidak diukur, tetapi mempengaruhi $\mathrm{Z}$

\section{Pengujian Hipotesis}

a. Pengaruh Secara Parsial Kompensasi $\left(\mathbf{X}_{1}\right)$ terhadap Kepuasan Kerja (Y)

Pengaruh Kompensasi secara parsial terhadap Kepuasan Kerja dapat diketahui melalui pengujian statistik dengan menggunakan hipotesis sebagai berikut :

$\mathrm{H}_{\mathrm{o}}: \rho \mathrm{yx}_{1}=0 \quad$ : Tidak terdapat pengaruh parsial antara Kompensasi terhadap Kepuasan kerja

$\mathrm{H}_{1}:$ pyx $1 \neq 0 \quad$ :Terdapat pengaruh parsial antara Kompensasiterhadap Kepuasan kerja

Kriteria uji: tolak $\mathrm{H} 0$ jika Sig. $<\alpha$ atau $t_{\text {hitung }}>t_{\text {tabel }}$

Untuk pengaruh Kompensasi $\left(\mathrm{X}_{1}\right)$ secara parsial terhadap Kepuasan Kerja (Y) dengan tingkat signifikan $(\alpha)=5 \%$, degree of freedom $(\mathrm{df})=\mathrm{n}-2=70-2=68$ diperoleh $\mathrm{t}_{\text {tabel }}=$ 1,664. Berdasarkan tabel 4.65 di atas, menunjukan bahwa thitung = 7,099 dan sig. 0,000. Pengaruh $\mathrm{X}_{1}$ secara parsial terhadap $\mathrm{Y}$ diperlihatkan pada tabel 4.80 sebagai berikut:

\section{Tabel 13}

\section{Pengaruh Parsial Kompensasi $\left(\mathrm{X}_{1}\right)$ terhadap Kepuasan Kerja (Y)}

\begin{tabular}{|c|c|c|c|c|c|}
\hline Structural & Sig. & A & thitung $_{\text {tabel }}$ & Kesimpulan \\
\hline pyx $_{1}$ & 0,000 & 0,05 & 7,099 & 1,664 & $\mathrm{H}_{0}$ ditolak \\
\hline
\end{tabular}

Sumber : Hasil Pengolahan Data SPSS, 2017

Tabel 4.80 menunjukan bahwa nilai sig. $(0,000)<\alpha(0,05)$ dan $t_{\text {hitung }}(7,099)>t_{\text {tabel }}$ $(1,664)$, maka $\mathrm{H}_{0}$ ditolak. Dengan demikian dapat disimpulkan bahwa Kompensasi berpengaruh secara parsial terhadap Kepuasan Kerja.

\section{b. Pengaruh Secara Parsial Motivasi $\left(\mathrm{X}_{2}\right)$ terhadap Kepuasan Kerja (Y)}

Pengaruh Motivasi $\left(\mathrm{X}_{2}\right)$ secara parsial terhadap Kepuasan Kerja (Y) dapat diketahui melalui pengujian statistik dengan menggunakan hipotesis sebagai berikut:

$\mathrm{H}_{\mathrm{O}}: \mathrm{yx}_{2}=0$ : Tidak terdapat pengaruh parsial terhadap Motivasi terhadap Kepuasan Kerja $\mathrm{H}_{1}: \rho \mathrm{x}_{2} \neq 0$ : Terdapat pengaruh parsial antara motivasi terhadap Kepuasan Kerja

Kriteria Uji: Tolak $\mathrm{H}_{0}$ jika Sig. $<\alpha$ atau $\mathrm{t}_{\text {hitung }}>\mathrm{t}_{\text {tabel }}$

Untuk pengaruh Motivasi $\left(\mathrm{X}_{2}\right)$ secara parsial terhadap Kepuasan $\mathrm{Kerja}(\mathrm{Y})$ dengan tingkat signifikan $(\alpha)=5 \%$, degree of freedom $(\mathrm{df})=\mathrm{n}-2=70-2=98$ diperoleh $\mathrm{t}_{\text {tabel }}=1,664$. Berdasarkan tabel 4.70 di atas, menunjukan bahwa thitung $=3,478$ dan sig. 0,001. Pengaruh $\mathrm{X}_{2}$ secara parsial terhadap Y diperlihatkan pada tabel 4.81 dibawah ini. 
Tabel 14

Pengaruh Parsial Motivasi $\left(\mathbf{X}_{2}\right)$ terhadap Kepuasan Kerja (Y)

\begin{tabular}{|c|c|c|c|c|c|}
\hline Structural & Sig. & $\mathbf{A}$ & $\mathbf{t}_{\text {hitung }}$ & $\mathbf{t}_{\text {tabel }}$ & Kesimpulan \\
\hline pyx $_{2}$ & 0,001 & 0,05 & 3,478 & 1,664 & $\mathrm{H}_{0}$ ditolak \\
\hline
\end{tabular}

Sumber : Hasil Pengolahan Data SPSS, 2017

Tabel 4.81 menunjukan bahwa nilai sig. $(0,007)<\alpha(0,05)$ dan $t_{\text {hitung }}(3,478)>t_{\text {tabel }}$ $(1,664)$, maka $\mathrm{H}_{0}$ ditolak. Dengan demikian dapat disimpulkan bahwa Motivasi secara parsial berpengaruh terhadap kepuasan kerja.

\section{c. Pengaruh Secara Parsial Kompensasi $\left(X_{1}\right)$ terhadap Kinerja $(Z)$}

Pengaruh Kompensasi secara parsial terhadap Kinerja dapat diketahui melalui pengujian statistik dengan menggunakan hipotesis sebagai berikut :

$\mathrm{H}_{\mathrm{o}}: \rho \mathrm{zx}_{1}=0 \quad$ : Tidak terdapat pengaruh Kompensasi terhadap Kinerja

$\mathrm{H}_{1}: \rho \mathrm{zx}_{1} \neq 0 \quad$ :Terdapat Pengaruh Kompensasi terhadap Kinerja

Kriteria uji : tolak H0 jika Sig. $<\alpha$ atau $t_{\text {hitung }}>t_{\text {tabel }}$

Untuk pengaruh Motivasi $\left(\mathrm{X}_{2}\right)$ secara parsial terhadap Kinerja $(\mathrm{Z})$ dengan tingkat signifikan $(\alpha)=5 \%$, degree offreedom $(\mathrm{df})=\mathrm{n}-2=70-2=68$ diperoleh $\mathrm{t}_{\text {tabel }}=1,664$. Berdasarkan tabel 4.71 di atas, menunjukan bahwa thitung $=2,023$ dan sig. 0,000. Pengaruh $\mathrm{X}_{1}$ secara parsial terhadap $\mathrm{Z}$ diperlihatkan pada tabel 4.78 sebagai berikut :

\section{Tabel 15}

\section{Pengaruh Parsial Kompensasi $\left(\mathrm{X}_{1}\right)$ terhadap Kinerja $(\mathrm{Z})$}

\begin{tabular}{|c|c|c|c|c|c|}
\hline Structural & Sig. & A & thitung $_{\text {tabel }}$ & Kesimpulan \\
\hline$\rho \mathrm{zX}_{1}$ & 0,000 & 0,05 & 2,023 & 1,664 & $\mathrm{H}_{0}$ ditolak \\
\hline
\end{tabular}

Sumber : Hasil Pengolahan Data SPSS, 2017

Tabel 4.80 menunjukan bahwa nilai sig. $(0,000)<\alpha(0,05)$ dan $t_{\text {hitung }}(2,023)>t_{\text {tabel }}(1,664)$, maka $\mathrm{H}_{0}$ ditolak. Dengan demikian dapat disimpulkan bahwa Kompensasi berpengaruh secara parsial terhadap Kinerja.

d. Pengaruh Secara Parsial Motivasi $\left(X_{2}\right)$ terhadap Kinerja $(Z)$

Pengaruh Motivasi $\left(\mathrm{X}_{2}\right)$ secara parsial terhadap Kinerja $(\mathrm{Z})$ dapat diketahui melalui pengujian statistik dengan menggunakan hipotesis sebagai berikut :

$\mathrm{H}_{\mathrm{o}}: \rho \mathrm{zx}_{2}=0$ : Tidak terdapat pengaruh parsial Motivasi terhadap Kinerja

$\mathrm{H}_{1}: \rho \mathrm{zx}_{2} \neq 0$ : Terdapat pengaruh parsial motivasi terhadap Kinerja

Kriteria Uji: Tolak $\mathrm{H}_{0}$ jika Sig. $<\alpha$ atau $\mathrm{t}_{\text {hitung }}>\mathrm{t}_{\text {tabel }}$

Untuk pengaruh Motivasi $\left(\mathrm{X}_{2}\right)$ secara parsial terhadap Kinerja $(\mathrm{Z})$ dengan tingkat signifikan $(\alpha)=5 \%$, degree of freedom $(\mathrm{df})=\mathrm{n}-2=70-2=98$ diperoleh $\mathrm{t}_{\text {tabe }} \mathrm{l}=1,664$. Berdasarkan tabel 4.71 di atas, menunjukan bahwa thitung $=2,593$ dan sig. 0,000. Pengaruh $\mathrm{X}_{2}$ secara parsial terhadap $\mathrm{Z}$ diperlihatkan pada tabel 4.83 dibawah ini.

\section{Tabel 16}

Pengaruh Parsial Motivasi $\left(\mathrm{X}_{2}\right)$ terhadap Kinerja $(\mathrm{Z})$

\begin{tabular}{|c|c|c|c|c|c|}
\hline Structural & Sig. & A & $\mathbf{t}_{\text {hitung }}$ & $\mathbf{t}_{\text {tabel }}$ & Kesimpulan \\
\hline$\rho \mathrm{zx}_{2}$ & 0,000 & 0,05 & 2,593 & 1,664 & $\mathrm{H}_{0}$ ditolak \\
\hline
\end{tabular}

Sumber : Hasil Pengolahan Data SPSS, 2017

Tabel 4.83 menunjukan bahwa nilai sig. $(0,000)<\alpha(0,05)$ dan $t_{\text {hitung }}(2,593)>t_{\text {tabel }}(1,664)$, maka $\mathrm{H}_{0}$ ditolak. Dengan demikian dapat disimpulkan bahwa Motivasi secara parsial berpengaruh terhadap Kinerja.

\section{e. Pengaruh Parsial Kepuasan Kerja (Y) Terhadap (Z)}

Pengaruh Kepuasan kerja terhadap Kinerja pegawai dapat diketahui melaluai pengujian statistik dengan menggunakan hipotesis sebagai berikut :

H0: Pzy $=0$ (tidak ada pengaruh) 
$\mathrm{H} 1:$ Pzy $\neq 0$ (ada pengaruh)

Hipotesis bentuk kalimat:

H0: Kepuasan kerja tidak berpengaruh terhadap kinerja pegawai

H1: Kepuasan Kerja berpengaruh terhadap kinerja pegawai

Untuk pengaruh Kepuasan Kerja (Y) terhadap Kinerja Pegawai $(\mathrm{Z})$ dengan tingkat signifikan $(\alpha)=5 \%$, degree of freedom $(\mathrm{df})=\mathrm{n}-2=70-2=68$ diperoleh $\mathrm{t}_{\text {tabel }}=1,664$. Berdasarkan tabel 4.71 di atas, menunjukan bahwa thitung $=1,890$ dan sig. 0,000. Pengaruh $\mathrm{X}_{1}$ secara parsial terhadap Y diperlihatkan pada tabel 4.84 sebagai berikut :

Tabel 17

Pengaruh Parsial Kepuasan Kerja (Y) Terhadap Kinerja (Z)

\begin{tabular}{|c|c|c|c|c|c|}
\hline Structural & Sig. & $\mathbf{A}$ & $\mathbf{t}_{\text {hitung }}$ & $\mathbf{t}_{\text {tabel }}$ & Kesimpulan \\
\hline pzy & 0,000 & 0,05 & 1,890 & 1,664 & $\mathrm{H}_{0}$ ditolak \\
\hline
\end{tabular}

Sumber : Hasil Pengolahan Data SPSS, 2017

Tabel 4.84 menunjukan bahwa nilai sig. $(0,000)<\alpha(0,05)$ dan $t_{\text {hitung }}(1,890)>t_{\text {tabel }}(1,664)$, maka $\mathrm{H}_{0}$ ditolak. Dengan demikian dapat disimpulkan bahwa Kepuasan Kerja berpengaruh signifikan terhadap Kinerja Pegawai.

\section{f. Pengaruh Simultan Kompensasi dan Motivasi Terhadap Kepuasan Kerja}

Pengaruh Kompensasi $\left(\mathrm{X}_{1}\right)$ dan Motivasi $\left(\mathrm{X}_{2}\right)$ secara Simultan (keseluruhan) terhadap Kepuasan Kerja (Y) dapat diketahui melalui pengujian statistik dengan menggunakan hipotesis sebagai berikut :

$\mathrm{H}_{\mathrm{o}}: \operatorname{\rho x}_{1} \mathrm{x}_{2}=0: \quad$ Tidak terdapat pengaruh Kompensasidan Motivasi terhadap Kepuasan Kerja

$\mathrm{H}_{1}: \rho \mathrm{yx}_{1} \mathrm{x}_{2} \neq 0$ : Terdapat pengaruh Simultan Kompensasi dan Motivasi terhadap Kepuasan Kerja

Kriteria Uji : $\quad$ Tolak $\mathrm{H}_{0}$ jika sig. $<\alpha$ atau $\mathrm{f}_{\text {hitung }}>\mathrm{f}_{\text {tabel }}$

Untuk Kompensasi $\left(\mathrm{X}_{1}\right)$ dan Motivasi $\left(\mathrm{X}_{2}\right)$ secara simultan terhadap Kepuasan Kerja(Y) dengan tingkat signifikan $(\alpha)=5 \%$, degree of freedom $(\mathrm{df})=\mathrm{n}-2=70-2=98$ diperoleh $\mathrm{f}_{\text {tabel }}=3,09$. Sedangkan $\mathrm{f}_{\text {hitung }}$ dapat dilihat dari tabel 4.85 dibawah ini :

Tabel 18

Hasil Perhitungan Nilai F

ANOVA ${ }^{\mathrm{a}}$

\begin{tabular}{|rl|r|r|r|r|r|}
\hline \multicolumn{2}{|l|}{ Model } & \multicolumn{1}{|c|}{$\begin{array}{c}\text { Sum of } \\
\text { Squares }\end{array}$} & Df & \multicolumn{1}{c|}{$\begin{array}{c}\text { Mean } \\
\text { Square }\end{array}$} & F & \multicolumn{1}{c|}{ Sig. } \\
\hline 1 & Regression & 5191.532 & 2 & 2595.766 & 743.830 & $.000^{\mathrm{b}}$ \\
& Residual & 233.812 & 67 & 3.490 & & \\
& Total & 5425.343 & 69 & & & \\
\hline
\end{tabular}

a. Dependent Variable: Y

b. Predictors: (Constant), X2, X1

Berdasarkan tabel 4.85 diatas, menunjukan bahwa $\mathrm{f}_{\text {hitung }}=743,830$ dan $\mathrm{si}^{9} .0,000$. Pengaruh $\mathrm{X}_{1}$ dan $\mathrm{X}_{2}$ secara Simultan terhadap Y diperhatikan pada tabel 4.86 di bawah ini:

\section{Tabel 19}

Pengaruh Simultan Kompensasi $\left(\mathrm{X}_{1}\right)$ dan Motivasi $\left(\mathrm{X}_{2}\right)$ terhadap Kepuasan Kerja (Y)

\begin{tabular}{|c|c|c|c|c|c|}
\hline Structural & Sig. & A & $\mathbf{f}_{\text {hitung }}$ & $\mathbf{t}_{\text {tabel }}$ & Kesimpulan \\
\hline$\rho \mathrm{yx}_{2}$ & 0,000 & 0,10 & 743,830 & 3,09 & $\mathrm{H}_{0}$ ditolak \\
\hline
\end{tabular}


Sumber : Hasil Pengolahan Data SPSS, 2017

Tabel 4.86 menunjukan bahwa nilai sig. $(0,000)<\alpha(0,10)$ dan $f_{\text {hitung }}(743,830)>t_{\text {tabel }}(3,09)$ maka $\mathrm{H}_{0}$ ditolak. Dengan demikian dapat disimpulkan bahwa Kompensasi dan Motivasi berpengaruh secara Simultan terhadap Kinerja Pegawai.

\section{g. Pengaruh Simultan Kompensasi, Motivasi dan Kepuasan Kerja Terhadap Kinerja}

Pengaruh Kompensasi $\left(\mathrm{X}_{1}\right)$, Motivasi $\left(\mathrm{X}_{2}\right)$ dan Kepuasan Kerja (Y) secara Simultan (keseluruhan) terhadap Kinerja (Z) dapat diketahui melalui pengujian statistik dengan menggunakan hipotesis sebagai berikut :

$\mathrm{H}_{\mathrm{o}}: \rho \mathrm{zyx}_{1} \mathrm{x}_{2}=0$ :Tidak terdapat pengaruh Kompensasi, Motivasi dan Kepuasan Kerja terhadap Kinerja

$\mathrm{H}_{1}: \operatorname{pzyx}_{1} \mathrm{X}_{2} \neq 0$ :Terdapat pengaruh Simultan Kompensasi, Motivasi dan Kepuasan Kerja terhadap Kinerja

Kriteria Uji : $\quad$ Tolak $\mathrm{H}_{0}$ jika sig. $<\alpha$ atau $\mathrm{f}_{\text {hitung }}>\mathrm{f}_{\text {tabel }}$

Untuk Kompensasi $\left(\mathrm{X}_{1}\right)$, Motivasi $\left(\mathrm{X}_{2}\right)$ dan Kepuasan Kerja $(\mathrm{Y})$ secara simultan terhadap Kinerja $(Z)$ dengan tingkat signifikan $(\alpha)=5 \%$, degree of freedom $(\mathrm{df})=\mathrm{n}-2=70-2=98$ diperoleh $\mathrm{f}_{\text {tabel }}=3,09$. Sedangkan $\mathrm{f}_{\text {hitung }}$ dapat dilihat dari tabel 4.87 dibawah ini :

Tabel 20

Hasil Perhitungan Nilai F $\mathbf{X}_{1}, \mathbf{X}_{2}, \mathrm{X}_{3}-\mathrm{Y}$ ANOVA $^{\mathrm{a}}$

\begin{tabular}{|ll|c|r|r|r|r|}
\hline \multicolumn{2}{|l|}{ Model } & \multicolumn{1}{|c|}{$\begin{array}{c}\text { Sum of } \\
\text { Squares }\end{array}$} & Df & Mean Square & F & Sig. \\
\hline 1 & Regression & 1431.000 & 3 & 477.000 & 7.490 & $.000^{\mathrm{b}}$ \\
& Residual & 4203.195 & 66 & 63.685 & & \\
& Total & 5634.195 & 69 & & & \\
\hline
\end{tabular}

a. Dependent Variable: $\mathrm{Z}$

b. Predictors: (Constant), Y, X2, X1

Berdasarkan tabel 4.87 diatas, menunjukan bahwa $\mathrm{f}_{\text {hitung }}=7.490$ dan si ${ }^{9} .0,000$. Pengaruh $\mathrm{X}_{1}$, $\mathrm{X}_{2}$ dan Y secara Simultan terhadap Z diperhatikan pada tabel 4.88 di bawah ini:

Tabel 21

Pengaruh Simultan Kompensasi $\left(\mathrm{X}_{1}\right)$ dan Motivasi $\left(\mathrm{X}_{2}\right)$ terhadap Kepuasan Kerja (Y)

\begin{tabular}{|c|c|c|c|c|c|}
\hline Structural & Sig. & A & f $_{\text {hitung }}$ & $\mathbf{t}_{\text {tabel }}$ & Kesimpulan \\
\hline$\rho \mathrm{yx}_{2}$ & 0,000 & 0,05 & 7.490 & 3,09 & $\mathrm{H}_{0}$ ditolak \\
\hline
\end{tabular}

Sumber : Hasil Pengolahan Data SPSS, 2017

Tabel 4.88 menunjukan bahwa nilai sig. $(0,000)<\alpha(0,05)$ dan $f_{\text {hitung }}(7.490)>t_{\text {tabel }}(3,09)$ maka $\mathrm{H}_{0}$ ditolak. Dengan demikian dapat disimpulkan bahwa Kompensasi, Motivasi dan Kepuasan Kerja berpengaruh secara Simultan terhadap Kinerja Pegawai.

\section{F. SIMPULAN}

Berdasarkan penelitian yang telah dilakukan maka kesimpulan yang dapat diambil mengenai Pengaruh kompensasi dan motivasi Terhadap Kepuasan kerja dan implikasinya nya 
pada kinerja pegawai Pada Pegawai Di lingkungan dinas pendidikan karawang adalah sebagai berikut :

1. Kompensasi pada Dinas Pendidikan Kabupaten Karawang dengan menggunakan 14 butir pernyataan terhadap variabel kompensasi yang berdasarkan hasil kuisioner diperoleh nilai dengan rata-rata sebesar 254,64. Hal ini menunjukan persepsi pegawai pada Dinas Pendidikan Kabupaten Karawang menyatakan setuju terhadap kompensasi yang diperoleh pegawainya di Dinas Pendidikan Kabupaten Karawang, tetapi masih terdapat indikator terendah Tunjangan pengobatan dan Pakaian Dinas . Motivasi pada Dinas Pendidikan Kabupaten Karawang dengan menggunakan 14 butir pernyataan terhadap variabel Motivasi yang berdasarkan hasil kuisioner diperoleh nilai dengan rata-rata sebesar 250,35. Hal ini menunjukan bahwa tanggapan pegawai di Dinas Pendidikan Kabupaten Karawang menyatakan setuju terhadap Motivasi yang diberikan Dinas Pendidikan Kabupaten Karawang namun masih ada indikator yang terendah yaitu Dihormati orang lain, Kondisi kerja dan Perilaku yang baik. Kepuasan kerja pada Dinas Pendidikan Kabupaten Karawang dengan menggunakan 14 butir pernyataan terhadap variabel kepuasan kerja yang berdasarkan hasil kuisioner diperoleh nilai dengan rata-rata 256,64. Hal ini menunjukan bahwa pegawai setuju terhadap kepuasan kerja pada Dinas Pendidikan Kabupaten Karawang tetapi masih ada indikator terendah yaitu Peluang promosi. Kinerja pegawai di Dinas Pendidikan Kabupaten Karawang dengan menggunakan 14 butir pernyataan terhadap variabel kinerja pegawai yang berdasarkan hasil kuisioner diperoleh nilai dengan rata-rata 248,35. Hal ini menunjukan bahwa kinerja pada pegawai Dinas Pendidikan Kabupaten Karawang sudah baik, namun masih ada indikator terendah yaitu keahlian .

2. Kompensasi secara parsial mempunyai pengaruh yang positif dan signifikan terhadap Kepuasan kerja. Koefisien jalur variabel Kompensasi secara parsial terhadap Kepuasan kerja adalah sebesar 0,662 dan besar total pengaruhnya (langsung + tidak langsung) sebesar 0,645 atau 64,5\%. Kompensasi lebih banyak memberikan pengaruh terhadap kepuasan kerja dibandingkan variabel Motivasi. Hal ini disebabkan karena responden mempunyai pandangan Kompensasi sangat mempengaruhi kepuasan kerja jika Kompensasi di nilai tidak bagus oleh para pegawai, maka pegawai tidak akan melakukan merasa puas.

3. Motivasi Secara parsial mempunyai pengaruh yang positif dan signifikan terhadap kepuasan kerja. Koefisien jalur variabel Motivasi secara parsial terhadap kepuasan kerja adalah sebesar 0,324. dan besar total pengaruhnya (langsung + tidak langsung) sebesar 0,311 atau $31,1 \%$.

4. Kompensasi secara parsial mempunyai pengaruh yang positif dan signifikan terhadap Kinerja. Koefisien jalur variabel Kompensasi secara parsial terhadap Kinerja adalah sebesar 0,447 dan besar total pengaruhnya (langsung + tidak langsung) sebesar 0,307 atau $30,7 \%$

5. Motivasi Secara parsial mempunyai pengaruh yang positif dan signifikan terhadap Kinerja. Koefisien jalur variabel Motivasi secara parsial terhadap Kinerja adalah sebesar 0,252. dan besar total pengaruhnya (langsung + tidak langsung) sebesar 0,172 atau 17,2\%.

6. Koefisien jalur variabel Kepuasan kerja terhadap kinerja pegawai adalah sebesar 0,424 dan besar total pengaruhnya (langsung) sebesar 0,180 atau $18 \%$.

7. Kompensasi dan Motivasi secara simultan mempunyai pengaruh yang positif dan signifikan terhadap Kepuasan kerja. Total pengaruh Kompensasi dan Motivasi terhadap Kepuasan kerja sebesar 95,6\%. Hal ini menunjukan bawa Kompensasi dan Motivasi memiliki kontribusi terhadap Kepuasan kerja sebesar 95,6\% sedangkan sisanya 4,4\% merupakan kontribusi variabel lain $(\varepsilon)$ yang tidak diteliti.

8. Kompensasi, Motivasi dan Kepuasan Kerja secara simultan mempunyai pengaruh positif dan signifikan terhadap Kinerja. Total pengaruh yang disebabkan Kompensasi, Motivasi 
dan Kepuasan Kerja terhadap Kinerja Pegawai yaitu sebesar 0,659 atau 65,9\%. Adapun pengaruh variabel lain diluar model adalah sebesar 0,341 atau $34,1 \%$.

\section{G. SARAN}

Adapun saran yang dapat dipertimbangkan sehubungan dengan hasil penelitian adalah sebagai berikut :

1. Diharapkan Dinas Pendidikan Kabupaten Karawang lebih meningkatkan Tunjangan pengobatan dan Pakaian Dinas agar Kepuasan kerja pegawai lebih meningkat. Hal ini menunjukan bahwa Kompensasi yang baik akan berpengaruh terhadap Kepuasan kerja. Diharapkan Dinas Pendidikan Kabupaten Karawang bisa lebih meningkatkan pada indikator Dihormati orang lain, Kondisi kerja dan Perilaku yang baik agar dapat memotivasi pegawai untuk mencapai tingkat kepuasan yang lebih tinggi. Diharapkan Dinas Pendidikan Kabupaten Karawang terus memberikan kesempatan peluang dan promosi bagi setiap pegawai agar dapat meningkatkan kepuasan kerja pegawainya. Diharapkan Dinas Pendidikan Kabupaten Karawang untuk lebih meningkatkan keahlian pegawainya agar kinerja pegawai semakin baik.

2. Dari penelitian yang telah dilakukan terhadap pengaruh parsial antara kompensasi terhadap kepuasan kerja sebesar 64,5\% dan terdapat pengaruh parsial antara Motivasi terhadap kepuasan kerja 31,1\%. Karena 31,1\% lebih kecil dari 64,5\% maka dapat dinyatakan Motivasi Dinas Pendidikan Kabupaten Karawang kurang memberikan konstribusi terhadap kepuasan kerja sehingga nilainya masih rendah. Responden mengharapkan Dinas Pendidikan Kabupaten Karawang agar lebih menigkatkan Motivasinya. Sehingga Dinas Pendidikan Kabupaten Karawang dapat bertahan dan lebih meningkatkan pelayanannya untuk dunia pendidikan di kabupaten Karawang.

3. Dari penelitian yang telah dilakukan terhadap pengaruh parsial antara kompensasi terhadap kinerja sebesar 30,7\% dan terdapat pengaruh parsial antara Motivasi terhadap kinerja sebesar 17,2\%. Karena 17,2\% lebih kecil dari 30,7\% maka dapat dinyatakan Motivasi Dinas Pendidikan Kabupaten Karawang kurang memberikan konstribusi terhadap kinerja pegawai sehingga nilainya masih rendah. Responden mengharapkan Dinas Pendidikan Kabupaten Karawang agar lebih menigkatkan Motivasi kepada para pegawainya sehingga kinerja pegawai dapat lebih meningkat lagi.

4. Dari penelitian yang telah dilakukan terhadap pengaruh parsial antara kepuasan terhadap kinerja sebesar 18\% dan Responden mengharapkan Dinas Pendidikan Kabupaten Karawang agar lebih meningkatkan tingkat kepuasan kerjanya. Sehingga kinerja pegawai dapat lebih baik lagi.

5. Dari penelitian yang telah dilakukan terdapat pengaruh secara simultan antara kompensasi dan Motivasi terhadap kepuasan kerja maka diharapkan Dinas Pendidikan Kabupaten Karawang agar dapat meningkatkan kompensasi dan motivasi kepada para pegawainya agar setiap pegawai dapat dapat mencapai kepuasan dalam bekerja

6. Dari penelitian yang telah dilakukan terdapat pengaruh secara simultan antara kompensasi dan Motivasi terhadap kepuasan kerja maka diharapkan Dinas Pendidikan Kabupaten Karawang agar dapat meningkatkan kompensasi dan motivasi kepada para pegawainya agar setiap pegawai dapat dapat mencapai kepuasan dalam bekerja.

7. Peneliti selanjutnya diharapkan dapat meneruskan penelitian ini dengan meneliti lebih lanjut, kesimpulan yang dihasilkan dari penelitian ini

8. Bagi peneliti selanjutnya sebaiknya penelitian dilakukan dengan metode penelitian yang lain misalnya dengan metode penelitian kualitatif. Dengan metode penelitian kualitatif peneliti dapat mengeksplorasi perasaan responden secara lebih mendalam secara langsung. Dengan demikian data yang diperoleh lebih akurat dan dapat mewakili dari seluruh 
populasi, selain itu untuk peneliti selanjutnya, penelitian dapat ditambah dengan variabel lain misalnya kepemimpinan, budaya organisasi dan sebagainya.

\section{H. DAFTAR PUSTAKA}

\section{Buku Dan Jurnal}

Ambar teguh sulistiyani, Rosidah. 2009. Manajemen Sumber Daya Manusia Konsep Teori dan Pengembangan dalam konteks organisasi public. Bandung: Graha Ilmu.

Bangun, Wilson.2012.Manajemen Sumber Daya Manusia. Jakarta: Erlangga

Buku Pedoman Penyusunan Tugas Akhir Mahasiswa S2 Manajemen. 2015. Fakultas Ekonomi Universitas Singaperbangsa Karawang

Fahmi, Irham, 2011. Manajemen Kinerja. Edisi ke Satu, Bandung: Alfabeta, Ferry Setiawan dan A. A. Sg. Kartika Dewi. 2013. Pengaruh Kepuasan Kerja

Terhadap Kinerja Karyawan Dan Kepuasan Pelanggan Pada Rumah Sakit Swasta Di Kota Denpasar. Jurnal Manajemen, Strategi Bisnis, dan Kewirausahaan Vol. 3, No.

5, Universitas Udayana, Bali (Diakses tangal 5 Mei 2017, 01:16)

Handoko, T Hani. 2008. Manajemen. Edisi 2. BPFE, Yogyakarta. 2012. Manajemen. BPFE, Yogyakarta.

Hasibuan, Malayu. S. P. 2011 Manajemen dasar Pengertian dan Masalah Edisi

Revisi .Jakarta: Bumi Aksara

Mangkunegara, A.A Anwar Prabu. 2008. Manajemen Sumber Daya Manusia Perusahaan. Bandung: Remaja Rosda karya.

Manullang. 2012. Dasar-Dasar Manajemen. Yogyakarta: UGM Gajah Mada University Press

Masydzulhak, Hapzi Ali dan Leni Dewi Anggraeni. 2016. The Influence of work Motivation and Job Satisfaction on Employee Performance and Organizational Commitment Satisfaction as an Intervening Variable in PT. Asian Isuzu Casting Center. Quest Journals Journal of Research in Business and Management Volume 4 Issue 10(2016) pp: 01-10 ISSN(Online) 2347-3002 Mercubuana University. (DiaksesTanggal 5 Mei 2017. 05.02)

Murty, Aprilia Windy dan Gunasti Hudiwinarsih. 2012. Pengaruh Kompensasi, Motivasi Dan Komitmen Organisasional Terhadap Kinerja Karyawan Bagian Akuntansi (Studi Kasus Pada Perusahaan Manufaktur Di Surabaya). Jurnal Volume 2, No. 2. ISSN 2086-3802 STIE Perbanas Surabaya (Diakses 10 Mei 2017. 01.03)

Ni Ketut Ayu Juli Astuti danI Nyoman Sudharma. 2013. Pengaruh Kompensasi Dan

Motivasi Terhadap Kepuasan Dan Kinerja Karyawan Pada Hotel Bakung's Beach Cottages Kuta-Bali. Jurnal Bisnis dan Manajemen Eksekutif Vol. 1 No. 2, Universitas Terbuka. (DiaksesTanggal 5 Mei 2017, 12:59)

Rivai,Veithzal. 2011. Manajemen Sumber Daya Manusia untuk Perusahaan.

Jakarta: Rineka Cipta. 2012. Manajemen Sumber Daya Manusia untuk Perusahaan.

Jakarta: Rineka Cipta.

Runik Puji Rahayu. 2010. Pengaruh Motivasi, Kepuasaan Kerja Dan Disiplin Kerja

Terhadap Kinerja Karyawan Di Universitas Madura Pamekasan. Tesis Program

Magister Manajemen Universitas Jember (Diakses Tanggal 1 Mei 2017, 00.18)

Sembiring, Masana. 2012. Budayadan Kinerja Organisasi. Focus media: Bandunng Siswanto, HB. 2010. Pengantar Manajemen. Jakarta: Bumi Aksara Silalahi, Uber. 2012. Metode Penelitian Sosial. Bandung: Refika Aditama Sopiah. 2008. Perilaku Organisasi. Edisi kesatu. Yogyakarta : Andi Sugiyono, 2012. Metode Penelitian Kuantitatif, Kualitatif, dan $R \&$ D. Penerbit 
Alfabeta, Bandung.

Sutrisno, Edy. 2009. Manajemen Sumber Daya Manusia. Jakarta: Kencana.

Suwatno \& Donni Juni Priansa. 2011. Manajemen SDM Dalam Organisasi Publik dan Bisnis, Alfabeta, Bandung.

Soelaiman Sukmalana. 2009. Manajemen Kinerja. Jakarta: Bumi Aksara

Usman, Husaini. 2011. Manajemen Teori Praktik dan Riset Pendidikan. Jakarta:Bumi Aksara

Wijaya, Tanto dan Fransiska andreani. 2015. Pengaruh Motivasi dan Kompensasi Terhadap Kinerja Karyawan Pada PT Sinar Jaya Abadi Bersama. Jurnal Vol. 3 No. 2. Universitas Kristen Petra Surabaya. (Diakses Tanggal 12 Mei 2017. 00.02)

Wiludjeng, Sri. 2007. Pengantar Manajemen. Yogyakarta: Graha Ilmu

Wayne, Pace, Don F Faules. 2010. Komunikasi Organisasi (Strategi Meningkatkan Kinerja Perusahaan). Editor Deddy Mulyana. Bandung: Remaja Rosdakarya

Zaenal Mustafa Elqadri, Priyono, Rahayu Puji Suci \& Teddy Chandra. 2015. Effect of Leadership Style, Motivation, and Giving Incentives on the Performance of Employees-PT. Kurnia Wijaya Various Industries. International Education Studies; Vol. 8, No. 10; 2015 ISSN 1913-9020 E-ISSN 1913-9039 Faculty of Economics, University of Islam Indonesia Yogyakarta. (Diakses Tanggal 13 Mei 2017. 00.02)

\section{Peraturan, Kebijakan dan Buku Pedoman}

1. Undang-Undang Nomor 20 Tahun 2003 tentang Sistem Pendidikan Nasional

2. Permendiknas Nomor 24 tahun 2008 tentang Standar Tenaga Administrasi Sekolah; dan Permendiknas Nomor 74 tahun 2008 tentang guru (Dokumen Rencana Strategis Dinas Pendidikan Kabupaten Karawang Tahun 2008-2012) 